Organisation for countries not represented on the International Council ; and contact will be made with the International Labour Office, the Food and Agriculture Organisation, the Economic and Social Council of the United Nations Organisation, and with the International Federation of Scientific Workers, in order to avoid duplication of work in so far as these bodies might have made inquiries of similar nature. The International Federation of Scientific Workers will also be approached concerning a charter of rights and obligations for scientific men.

\section{Marconi Jubilee and Congress in Rome}

As already recorded in Nature (May 3, 1947, p. 598 ), it is just fifty years ago that Marconi gave the first successful demonstration of wireless signalling in Great Britain. The fiftieth anniversary of the foundation of the Marconi Company was on July 20, and to mark the occasion a souvenir brochure was produced ("Jubilee Year, The Marconi Company." Pp. 58. Published by Marconi's Wireless Telegraph Co., Ltd., Chelmsford, 1947). This volume provides a brief and very interesting account of the development of wireless signalling by the Company, from the first practical transmissions over a few miles to the achievements attained in the fields of broadcasting, television and radar. The brochure is profusely illustrated by a large number of excellent photographs, many of which have a unique historical interest.

To mark the occasion of the Marconi Jubilee, the Italian National Council of Research held an Inter. national Congress in Rome during September 28October 4. The Congress was attended by about two hundred delegates from some twelve countries : there were seven British delegates representing the Royal Society, Physical Society, Institution of Electrical Engineers, Government departments, both civil and military, and the radio industry. The technical part of the Congress comprised the presentation of a large number of scientific and technical papers describing progress in various fields of radio technique during the past twenty years or so. It is understood that these papers will be collected together and published in a special commemoration volume. Apart from one or two social events, the Congress visited the main transmitting station of the Italian Radio and Cable Co., some ten miles out of Rome. This station was extensively damaged during the War; but several long-distance short-wave circuits are now in operation. A special visit was also paid to Castel Gandolfo, at which the whole Congress was addressed by the Pope. The programme of celebrations provided the usual opportunities of meeting delegates from other countries and discussing matters of mutual interest in radio and allied fields.

\section{Development of Insecticides and Weed-killers}

Ten years ago, Plant Protection, Ltd., was formed to take over the agricultural and horticultural interests of Imperial Chemical Industries, Ltd., and Cooper, Macdougall and Robertson, Ltd., and a dinner was held recently in London to celebrate the achievements of the first decade. Replying to the toast of "Agriculture" proposed by Mr. S. W. Cheveley, managing director of the firm, Prof. Scott Watson outlined some of the remarkable advances made in recent years in the discovery and production of new insecticides and selective weed-killers. Plant Protection, Ltd., has been in the forefront of these advances. It has recruited research workers and formed an advisory service to study all aspects of the products that it markets, and give advice on how to use them. This service is international in scope. The Research Station at Fernhurst, which was taken over nearly two years ago, serves as a training centre for the technical staff as well as a research centre and demonstration centre. The Imperial Chemical Industries research stations of Hawthorndale and Jealott's Hill examine chemicals that may prove useful in plant culture, from the whole of the Imperial Chemical Industries organisation, and those that prove useful are passed on to Plant Protection, Ltd., for technical development, which is carried out at Yalding and Fernhurst. In addition, chemicals from sources outside Imperial Chemical Industries are examined and may be in. corporated in the firm's range of products. Perhaps the firm's most notable contribution to the field of pəst control is the production of $1,2,3,4,5,6$-hexachlorocyclohexane in the 'Agrocide' range of products containing 'Gammexane'; but notable contributions have also been made to the study of plant hormones and the technique of application of seed dressings. The firm has also at its disposal the accumulated experience of Cooper, Macdougall and Robertson, Ltd., in the field of derris insecticides, a field in which they were pioneers. Plant protection is becoming, or has become, a matter for specialists, and Plant Protection, Ltd., has recognized this fact and is organising accordingly.

The Profession of Chemistry in India and Pakistan

Prof. Alexander Findlay, past president of the Royal Institute of Chemistry, accompanied by Mrs. Findlay, is to visit important centres of scientific activity in India and Pakistan. The main purpose of his mission is to study the steps that are being and might be taken in the two Dominions to ensure that due provision will be made, and on an increasing scale, for students to receive proper training in the science of chemistry and for a fuller recognition of the status of the profession. Prof. Findlay hopes to be present at the meeting of the Indian Science Congress and the annual meeting of the Indian Section of the Royal Institute of Chemistry at Patna in January 1948, as well as at the subsequent inauguration of the examinations for the associate. ship of the Institute at Bangalore.

\section{Estimated Weight of the Largest Bird}

IN The Condor of July-August 1947 (49, No. 4), Dean Amadon gives an account of an investigation which he has made into the weight of the largest known bird. The ostrich (Struthio camelus), largest of living birds, was far surpassed in size by the elephant bird (Aepyornis maximus) of Madagascar; the larger of the New Zealand moas such as Dinornis were intermediate in size. The moas and elephant birds were exterminated by the natives of these islands and are known only from sub-fossil remains of skeletons, eggs and feathers. From available evidence, Amadon estimates that Aepyornis maximus weighed about 965 pounds and Dinornis about 520 pounds. This compares with a weight of about 250 pounds for the ostrich.

\section{A Study of Cultural Phenomena}

IN an article entitled "The Expansion of the Scope of Science" ( $J$. Washington Acad. Sci., 37, No. 6 ; June 15, 1947), Leslie A. White attempts to assess the ages and degrees of maturity of the sciences. The following 'law' is stated: "Scientific interpretation 